Original Article

\title{
KNOWLEDGE REGARDING CARDIOVASCULAR RISK FACTORS AMONG PEOPLE IN SOUTH INDIA: A COM MUNITY BASED STUDY
}

\author{
Joby Francis ${ }^{1}$, Josmi Jose ${ }^{1}$, Joyse K. Sunny ${ }^{1}$, Juvairiya U.S. ${ }^{1} \&$ Sanil Varghese ${ }^{2}$ \\ ${ }^{1}$ Students P.B.B.Sc (N), Yenepoya Nursing College, ${ }^{2}$ Lecturer, Department of M edical Surgical Nursing, \\ Yenepoya University, M angalore, Karnataka , INDIA \\ Correspondence \\ Sanil Varghese \\ Lecturer, Department of Medical Surgical Nursing, Yenepoya Nursing College, M angalore - 575 018, India, Karnataka, India. \\ E-mail : sanilmlore@gmail.com
}

\begin{abstract}
:
Coronary Heart Disease (CHD) is the leading cause of death in the world. While it is well established as the foremost contributor to mortality in most developed countries, it is also a major and rapidly rising cause of death in many developing countries. To assess the existing knowledge of people regarding cardiovascular risk factors. This community based descriptive study was conducted to assess the knowledge regarding cardiovascular risk factors among community people. They were selected through Non probability convenient sampling and pre-validated semi-structured questionnaire related to various aspects of cardiovascular risk factors used. The data was analyzed using SPSS version 16 and the results expressed as proportion. A total of 100 community people surveyed, majority of the participants (98\%) had average level of knowledge regarding cardiovascular risk factors. There was a significant association between knowledge and age $\left(\chi^{2}=5.09, p<0.05\right)$. There was a significant association between knowledge and education $\left(\chi^{2}=4.38, p<0.05\right)$. M ajority of the participants $(76 \%)$ did not have family history of heart diseases. The study reflects that majority of the participants (98\%) had average level of knowledge regarding cardiovascular risk factors. Hence it is necessary to educate the people in community regarding cardio vascular riskfactors.
\end{abstract}

Keywords: Knowledge, people, cardiovascular riskfactors.

\section{Introduction :}

The most important determinant of cardiovascular health is a person's age. By 2013, approximately $20 \%$ of the population will be aged 65 or older. In this age group cardiovascular disease will result in $45 \%$ of all deaths and rank as the leading cause. Furthermore, the cost to treat cardiovascular disease will triple in that time. Hence, it remains a vital that we understand age is such a critical component of cardiovascular disease etiology. ${ }^{1}$

Cardiovascular disease is the world's leading killer, accounting for 16.7 million deaths or $29.2 \%$ of the total number of global deaths in 2003. While deaths from heart attacks have declined more than $50 \%$ since the 1960s in

\begin{tabular}{|c|}
\hline Access this article online \\
\hline Quick Response Code \\
\hline
\end{tabular}

many industrialized countries, $80 \%$ of global cardiovascular-diseaserelated deaths now occur in low- and middle-income nations, which cover most countries in Asia. ${ }^{2}$
In India in the past five decades, rates of coronary disease among urban populations have risen from $4 \%$ to $11 \%$. The World Health Organization (WHO) estimates that $60 \%$ of the world's cardiac patients will be Indian by $2020{ }^{3}$

In India, the leading cause of death is cardiovascular disease. At the same time, it has been found that cardiovascular disease is third overall in the burden of disease, the other two being infectious and parasitic diseases and unintentional injuries. In India, death from coronary heart disease rose from 1.17 million in 1990 to 1.59 million in 2000 and was 2.03 million in 2010. The prevalence varies by site, age group studied, and diagnostic criteria used, but an urban prevalence of about $10 \%$ in adults aged $\geq 35$ years old is a credible estimate based on several surveys. ${ }^{4}$

\section{Materials and Methods:}

This community based descriptive study was undertaken in Mangalore, Karnataka, India. Ethical clearance for the study was obtained from the Institutional Ethics 
Committee of Yenepoya University. The study population consisted of community people from M angalore. Samples were selected for the study by a non-probability convenient sampling method. The participants were briefed about the nature of the study, consent was given and a pre-tested semi-structured questionnaire administered to them. The information pertaining to basic physiology of heart, nutrition related to cardiovascular disease, risk factors, treatment and prevention of cardiovascular disease were included in the questionnaire. The investigators were present in case the respondents required assistance. A face to face interview schedule was used to collect the data. The data was analysed using SPSS version 16.00 and summarised as proportions.

\section{RESULTS}

Section I: Demographic variables of the samples.

Figure 1: Cylindrical diagram representing Distribution of subjects according to the Age

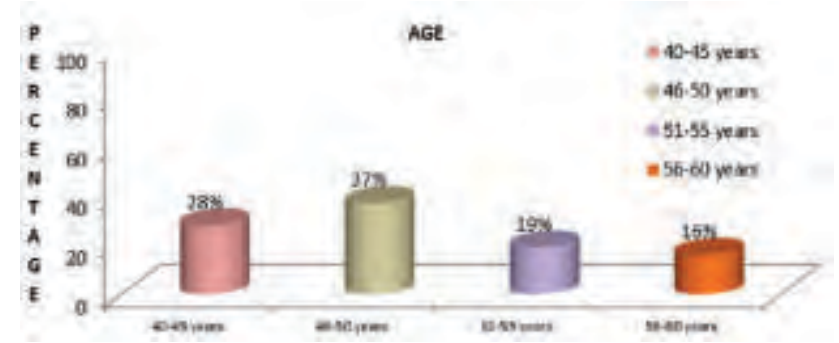

Figure 2: Pie chart representing Distribution of subjects according to the Gender

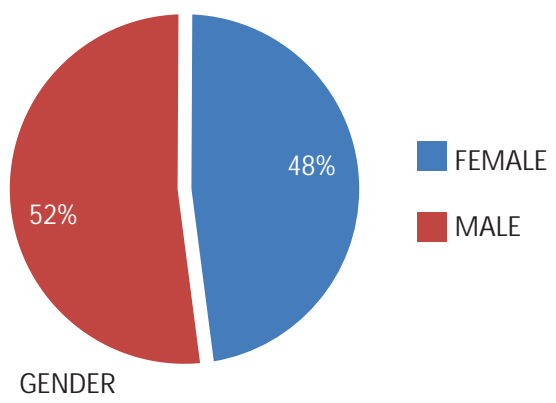

Figure 3: Bar diagram representing Distribution of subjects according to the Occupation.

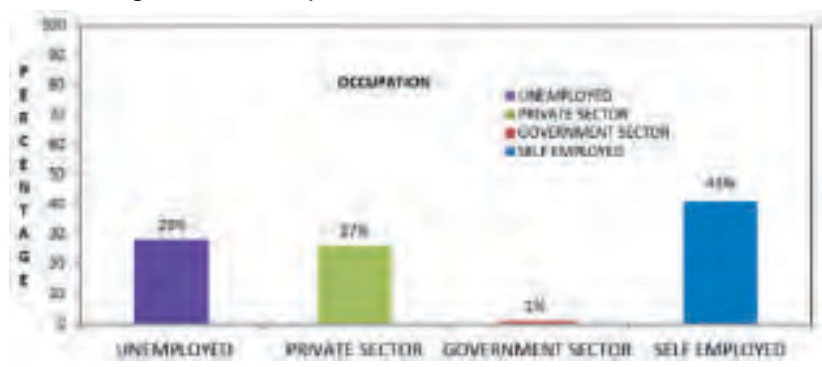

Figure 4: Cone Diagram Representing Distribution of subjects according to the Educational status.

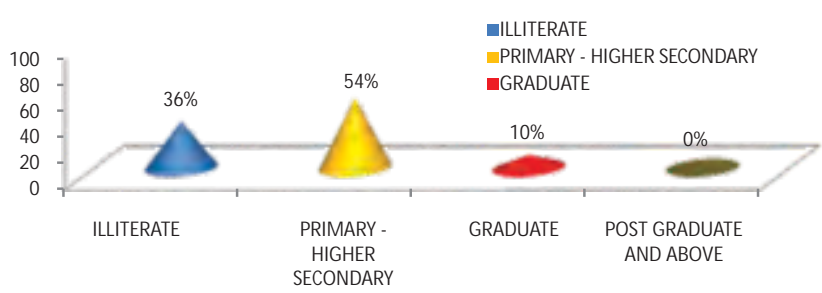

Figure 5: A pyramid showing that distribution of sample according to the sources of information.

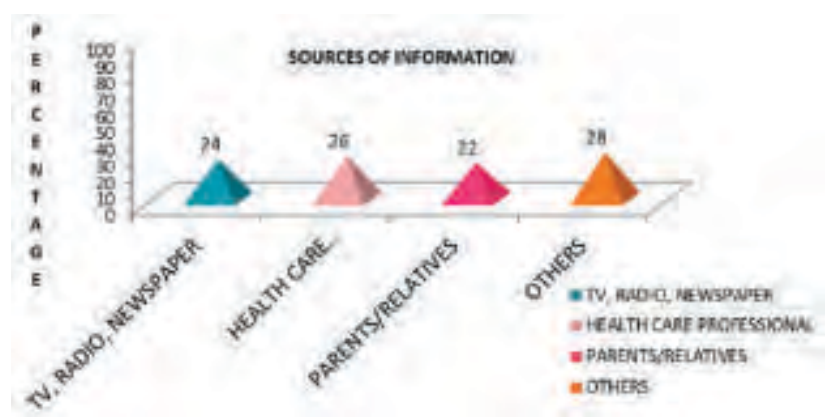

Figure 6: Pie chart representing Distribution of subjects according to the family history.

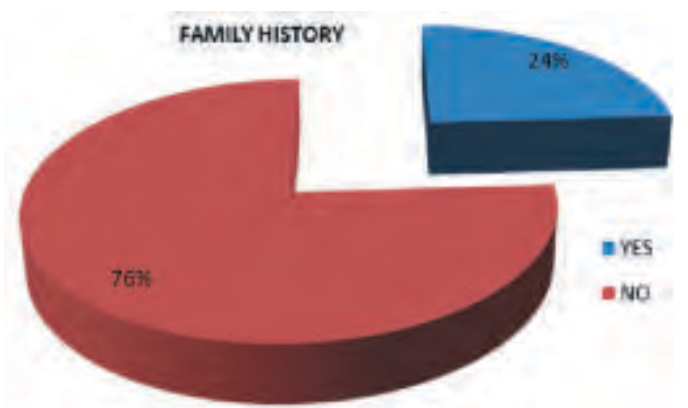

Most (37\%) of the subjects belonged to the age group of $46-50$ years, majority of the people were males (52\%) and only $48 \%$ were females. Majority of the people were self employed (43\%) and minority of the people were government sectors (1\%). Majority of the subject (54\%) had primary to higher secondary and least were graduate (10\%). M aximum of the subjects (28\%) had received information from other source. M ost of the subjects (76\%) had no family history of cardiovascular disease. 
Table 1: Frequency and percentage distribution according to the grading of their knowledge score $n=100$

\begin{tabular}{|c|c|c|c|}
\hline Knowledge score & Grading & Frequency & Percentage \\
\hline $0-10$ & Poor & 1 & 1 \\
\hline $11-20$ & Average & 98 & 98 \\
\hline $21-30$ & Good & 1 & 1 \\
\hline
\end{tabular}

The data presented in table 1 shows that majority of the people belongs to average level of knowledge $(98 \%)$, and $1 \%$ each of the participantshave poor and good level of knowledge.

\section{Section 2: Analysis of knowledge of people regarding} cardiovascular risk factors.

Table 2: Overall mean, median, SD and mean percentage of knowledgescore $n=100$

\begin{tabular}{|l|c|c|c|c|c|}
\hline Max possible score & Range & Mean & Median & SD & M ean\% \\
\hline 30 & $21-10$ & 15.15 & 15 & 2.34 & 50.5 \\
\hline
\end{tabular}

Table 2 shows that mean percentage of knowledge score of participant is $50.5 \%$.

Section 3: Association between knowledge score with selected demographic variables.

Table 5: Association between knowledge score \& selected demographic variables

$n=100$

\begin{tabular}{|c|c|c|c|c|}
\hline SI no. & Variables & < Mediar & Median & $x^{2}$ \\
\hline & & $n(15)$ & $n(15)$ & (df) \\
\hline 1. & Age in years & & & \\
\hline & $40-50$ years & 17 & 48 & $5.09 *$ \\
\hline & $51-60$ years & 17 & 18 & (1) \\
\hline 2. & Gender & & & \\
\hline & Female & 14 & 34 & 0.95 \\
\hline & Male & 20 & 32 & (1) \\
\hline 3. & Occupation & & & \\
\hline & $\begin{array}{l}\text { Unemployed, } \\
\text { Private sector }\end{array}$ & 19 & 39 & $\begin{array}{l}0.094 \\
(1)\end{array}$ \\
\hline & $\begin{array}{l}\text { Government sector, } \\
\text { Self employed }\end{array}$ & 15 & 27 & \\
\hline 4. & Educational status & & & \\
\hline & Illiterate, & 17 & 19 & $4.38^{*}$ \\
\hline & $\begin{array}{l}\text { Primary to post } \\
\text { graduate. }\end{array}$ & 17 & 47 & (1) \\
\hline 5. & Sources of information & & & \\
\hline & $\begin{array}{l}\text { TV, Radio, Newspaper } \\
\text { From health care } \\
\text { professional }\end{array}$ & 16 & 34 & $\begin{array}{l}0.178 \\
(1)\end{array}$ \\
\hline & $\begin{array}{l}\text { From parents / relatives / } \\
\text { Others }\end{array}$ & 18 & 32 & \\
\hline 6. & Do you have a family hist & $y$ of hea & disease & \\
\hline & Yes & 7 & 17 & $\$ 0.106$ \\
\hline & No & 27 & 49 & (1) \\
\hline
\end{tabular}

Table value $\chi 2_{(1)}=3.84 ; p<0.05 ; \chi 2_{(2)}=5.99 ; p<0.05 ; *$ significant; \$ Yates correction for chi-square test
Chi- square was computed to find the association between knowledge of the community people and demographic variables. There was a significant association between knowledge and age $\left(\chi \chi_{\text {calc (1) }}=5.09, \chi_{\text {tab(1) }}^{2}=3.83, p \varangle 0.05\right)$. And there was a significant association between knowledge and education $\left(\chi_{\text {calc }(1)}=4.38, \quad \chi_{\text {tab(1) }}^{2}=3.83, p<0.05\right)$ which indicated that knowledge scores were influenced by these demographic variables and the research hypothesis was accepted whereas there was no association between knowledge of cardiovascular risk factors and variables like gender, occupation, sources of information and family history.

\section{Discussion :}

In this study a significant association between knowledge and age $\left(\chi_{\text {calc (1) }}^{2}=5.09, \chi_{\text {tab(1) }}^{2}=3.83, p<0.05\right)$. Its is consistent with the findings of a cohort study done among 51,529 US male health professionals aged 40-75 years. The result showed that, there was a significant association between knowledge level and age.

In this study findings showed that $98 \%$ of the samples had average knowledge and $1 \%$ each of the samples had poor and good level of knowledge regarding cardiovascular risk factors. A significant association between knowledge and education $\left(\chi_{\text {calc(1) }}^{2}=4.38, \chi_{\text {tab(1) }}^{2}=3.83, p \varangle 0.05\right)$ was found in this study.

The following studies support the findings of the present study: A study was conducted among 1619 participants at Greece in 2002. The result revealed that coronary risk increases by $82 \%(p \varangle 0.05)$ for individuals with a lower level of education, and by $65 \%$ for individuals with an average education, compared to those with an academic education. ${ }^{6}$

A cross sectional study was conducted at All India Institute of M edical Sciences (AlIMS), a major tertiary care hospital in New Delhi, India among 217 Participants to assess their knowledge of modifiable risk factors of CAD. The result showed that there was a statistically significant; a trend towards a good knowledge level was associated with higher levels of education. 
A cross sectional study was conducted in Universities and colleges of Karachi East, among 200 adult students of different non-medical universities and colleges to assessment of knowledge of risk factors on CAD. The result showed that there was a significant; towards knowledge level was associated with higher levels of education. ${ }^{8}$

\section{Conclusion :}

The following conclusions were drawn on the basis of the findings of the study:

1 There were $98 \%$ of the samples had average knowledge and $1 \%$ each of the participants had poor and good knowledge regarding cardiovascular riskfactors.

\section{References:}

1. Reddy NK, Kumar DN, Rayudu NV, Sastry BK, Raju BS. Prevalence of risk factors for coronary atherosclerosis in a cross-sectional population.

2. Walsh B. Asia's war with heart disease time. 2004. p. 164.

3. World Health Organization. World health report: reducing risks, promoting healthy life. Geneva: WHO; 2002.

4. M cKeigue PM, Ferrie JE, Pierpont T, M armot M G. Association of earlyonset coronary heart disease in South Asian men with glucose intolerance and hyperinsulinemia. Circulation. 1993;87:152-61.

5. Juster RP, Sindi S, Marin MF, Perna A, Hashemi A, et al. A clinical allostatic load index is associated with burnout symptoms and hypocortisolemic profiles in healthy workers. Psychoneuroendocrinology

6. Christos E, Pistavos, DemosthenesB, Panagiotakos, Christina A, Chrysohoou et al. Education and acute coronarysyndromes: result from the CARDIO 2000 epidemological study. Bulletin of world health organization 2002; 80(5): 371 - 376.

7. Dickerson SS, Kemeny ME. Acute stressors and cortisol responses: a theoretical integration and synthesis of laboratory research. Psychol Bull. 2004;130:355-391.

8. Stergiopulos N, M eister JJ, Westerhof N. Simple and accurate way for estimating total and segmental arterial compliance: the pulse pressure method. Ann Biomed Eng. 1994;22:392-397.
I There is positive co-relation between knowledge score and selected demographic variables.

I There was a significant association between the knowledge score and selected demographic variables such as age and education.

\section{Acknowledgement:}

We would like to express our gratitude to the participants from $M$ angalore community area. We would equally thank Mr. Babu D, HOD, Dept of Medical surgical nursing, Yenepoya Nursing College, Mangalore for his kind suggestions in this endeavour. 